\title{
Hippocampal Place Cells: Stereotypy and Plasticity
}

\author{
Charles R. Breese, Robert E. Hampson, and Sam A. Deadwyler \\ Department of Physiology and Pharmacology, Bowman Gray School of Medicine of Wake Forest University, \\ Winston-Salem, North Carolina 27103
}

\begin{abstract}
Hippocampal complex spike cells were recorded during exploration for water delivered to cups located in various regions of an elevated platform. Place fields were recorded with a video monitoring system that recorded movements as the animal explored each of the 5 cup locations where water was delivered on the platform. Plasticity of place cell firing as a function of selective water delivery to specific cup locations on the platform was also examined. Several characteristics of place cell firing were studied that indicated a high degree of control by factors such as relative direction of movement and trajectory through the field. Time-shift analyses indicated cell firing was most representative of the place field at the time of spike occurrence. It was demonstrated that place fields possess borders in which firing was increased or decreased upon entering or leaving a particular region of the platform. The most important finding from this investigation was the pronounced degree of plasticity exhibited by place cells. Selective delivery of water to a single location on the platform was sufficient in most of the cases tested to shift the location of the field to the location where water was available. These findings suggest hippocampal place cell firing, although highly influenced by spatial and directional features of the environment, can readily change under conditions in which significant stimuli are added or removed from those locations.
\end{abstract}

The sensitivity of the hippocampal formation to distinct spatial features of the environment has been a topic of increasing interest in the last decade. Commencing with the first report by O'Keefe and Dostrovsky (1971) of the existence of place-sensitive cell firing in the hippocampus, and culminating in the theory by O'Keefe and Nadel (1978) of the hippocampus as a cognitive map, the notion of hippocampal involvement in the processing of spatial information is now widely accepted. The existence of cells within the hippocampus that respond to the spatial features of the environment suggests that processing of sensory information by this structure results in knowledge of the spatial relations between the animal and objects it encounters as it traverses its environment. It has been shown that place cell firing can be disrupted by disorienting the animal (Hill and

Received Mar. 7, 1988; revised Aug. 30, 1988; accepted Aug. 30, 1988

This work was supported by NIDA Grants DA03502 and DA04441, and DA00119 Research Scientist Award to S.A.D. We wish to thank Sonia Stitcher for her excellent assistance in preparing the manuscript.

Correspondence should be addressed to Sam A. Deadwyler, Ph.D., Department of Physiology and Pharmacology, Bowman Gray School of Medicine, $300 \mathrm{~S}$. Hawthorne Road, Winston-Salem, NC 27103.

Copyright (C) 1989 Society for Neuroscience $0270-6474 / 89 / 041097-15 \$ 02.00 / 0$
Best, 1981) or altering the environment by rearranging or removing salient cues (O'Keefe and Conway, 1978; O'Keefe, 1979).

Recently, more detailed analyses of place cells have provided additional insight into the spatial features that control their discharge. Muller et al. (1987) analyzed hippocampal place cell firing in rats in a well-controlled environment and described several manipulations to which place cells were sensitive. These included distance from the center of the place field, scaling of the dimensions of the apparatus, rotation of sensory cues within the environment, and placement of barriers within the field. These investigators concluded that a "kinematic" analysis best described place cell firing based on the finding that barriers restricting the predisposed movements through the field diminished place cell firing in most cells tested. It has been proposed that the stimulus configuration in which the animal is placed influences place cell firing via cognitive representations of the relationships between objects within the environment (Zipser, $1985,1987)$. Since hippocampal place fields never encompass the total environment in which they are tested, the existence of different fields within the same environment reflects possible connections of hippocampal cells with different segments of the visual field (Zipser, 1985, 1987; O'Keefe and Speakman, 1987).

In the studies reported here, place cell firing was examined in detail under conditions in which several of the above features could be evaluated quantitatively. It is shown that place fields of hippocampal cells are not fixed and can shift quite readily as a function of changes in the significance of locations within the environment that do not alter the properties or relations among spatial cues.

\section{Materials and Methods}

Surgery. Male Sprague-Dawley $(n=10)$ and Long-Evans rats $(n=3)$ $250-350 \mathrm{gm}$ were anesthetized with sodium pentobarbital $(35 \mathrm{mg} / \mathrm{kg})$ supplemented with chloral hydrate $(300 \mathrm{mg} / \mathrm{kg})$, and placed in a stereotaxic apparatus for surgical implantation of a removable microdrive assembly (Deadwyler et al., 1979a). The microdrive was designed to hold etched, insulated, tungsten wire recording electrodes (1-5 $\mu \mathrm{m}$ tip diameter). The base of the microdrive was positioned by physiological monitoring of spontaneous cell activity and affixed to the skull with dental cement. The mounting base was positioned to allow the recording electrode to traverse the CA1 cell layer of the hippocampus (coordinates: 3.8-4.0 $\mathrm{mm}$ posterior and 3.0-3.2 $\mathrm{mm}$ lateral to bregma) (Deadwyler et al., 1979b; Christian and Deadwyler, 1986). An uninsulated stainless steel wire $(100 \mu \mathrm{m})$ was inserted into the frontal cortex and served as a permanent reference electrode. Bicillin (penicillin 35,000 $\mathrm{U}$ ) was administered intramuscularly and Neosporin antibacterial ointment applied around the wound edges following surgery. Animals were allowed to recover their preoperative weights before initiation of experimental procedures (usually $5-7 \mathrm{~d}$ ).

Apparatus. The recording environment consisted of a flat-black painted platform, $56 \times 56 \mathrm{~cm}$, raised $41 \mathrm{~cm}$ from the floor, and surrounded on all sides by a black curtain. The curtain enclosure encompassed an 


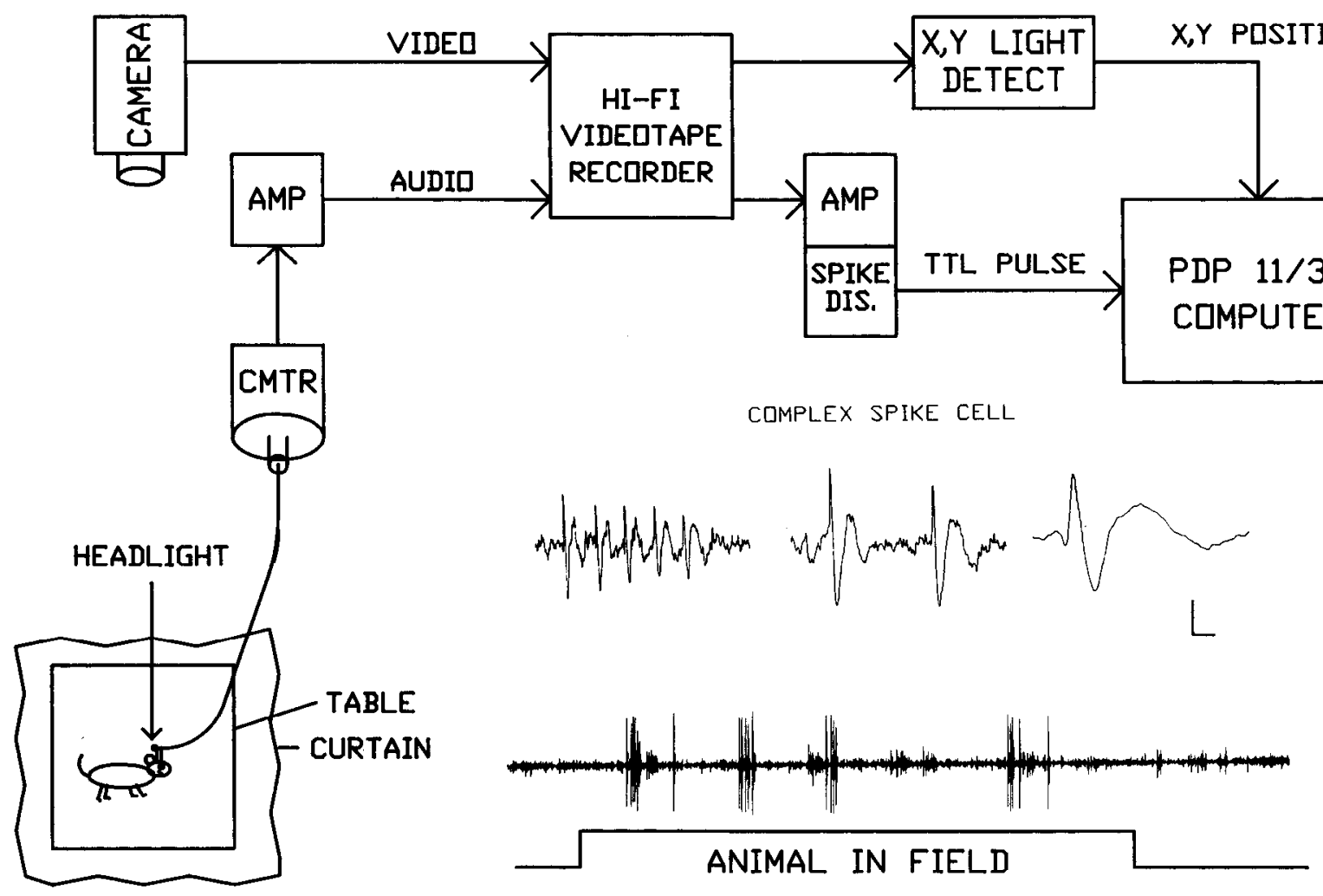

Figure 1. Block diagram of behavioral and electrophysiological recording apparatus. Analog signals from the recording electrode were transmitted via the recording cable through a commutator to a $1000 \times$ amplifier and high-pass filter. Animal position is monitored by a TV camera suspended over the platform (table). The filtered neural spike data and TV signal recorded simultaneously on the audio and video channels of a videotape recorder. Analog signals were spike discriminated, and the video record of the animal's movements analyzed by an $x$ and $y$ position video detector. The position coordinates and spike pulses were digitized and stored on a PDP-11/34 computer. Inset, Representative complex spike cell records are shown at different time bases. Calibration: $2.0,1.0$, and $0.25 \mathrm{msec}$ left to right; amplitude, $300 \mu \mathrm{V}$. Bottom trace, 2.0 sec total time of recording.

area $80 \times 80 \mathrm{~cm}$ and extended $80 \mathrm{~cm}$ above the platform. Small water cups (diameter $1.30 \mathrm{~cm}$ ) were located at the 4 corners and center of the platform. Drops of water $(50 \mu \mathrm{l})$ were delivered to the cups by a pressurized valve and manifold system controlled from outside the curtain. A large white cue card $(50 \times 50 \mathrm{~cm})$ was attached to one wall of the enclosure to serve as a reference stimulus. The platform and curtain enclosure were housed in a small research cubicle that contained video and electrophysiological recording equipment.

Adaptation, exploratory activity, and isolation of place cells. Animals were deprived of water for $24 \mathrm{hr}$ and acclimated to the apparatus by allowing them to explore the platform and find water in each of the 5 cups. Water was delivered randomly to 1 of the 5 water cups at approximately $30 \mathrm{sec}$ intervals to ensure traversal of all areas of the platform. Recording of unit activity commenced after the animals would explore the apparatus without showing prolonged bouts of inactivity (1-5 acclimation sessions). Prior to each recording session the animal was placed in a small enclosure with the microdrive attached. Cells were then isolated by slowly lowering the electrode with the microdrive into the CAl area of the hippocampus. Histological analysis of electrode placement confirmed that the location of the recording electrode was area CAl as estimated by its depth in the brain $(2.0-3.0 \mathrm{~mm}$ below the surface). Cells were identified as complex spike cells (Fig. 1, inset) based on multiple spike bursts and other published criteria (Fox and Ranck, 1981; Christian and Deadwyler, 1986; Foster et al., 1987). Once a cell with a signal-to-noise ratio of $\geq 3: 1$ was isolated, the animal was placed on the platform and attached to a recording cable. Cell activity was recorded for 7-10 min sessions, and during this time location specific firing (i.e., a place field) was determined. All cells demonstrating place fields were designated as "place cells." Following demonstration and verification of a place field, several manipulations were employed to examine factors controlling place field firing, including rotating the cue card to a different wall of the enclosure, introducing barriers at strategic places on the platform, and selectively delivering water to only 1 or 2 of the water cup locations.

Electrophysiological and video recording. A continuous video record of the experiment was obtained from a high-resolution black-and-white closed-circuit TV camera suspended $170 \mathrm{~cm}$ above the platform. The unit recording and video tracking arrangement utilized is shown in Figure 1. Video data was recorded on a Beta format Hi-Fi videotape recorder (SL-HF 400, Sony Corp., Park Ridge, NJ). Identified place cell activity (extracellular action potentials) was amplified 1000 times, filtered by a high-pass filter, and recorded on the audio channels of the video tape.

Animal position was determined using a video tracking device (VP112, HVS Image Analyzing, Kingston, UK). The tracking area was a square field $65 \mathrm{~cm}$ on a side that included approximately $5 \mathrm{~cm}$ beyond each edge of the platform to accommodate the animal's head extending off the edge of the platform. The output of the tracking device was two 8bit words containing the $x$ and $y$ coordinates of a high-contrast light source mounted on the recording cable $5 \mathrm{~cm}$ above the animal's head. Unit recordings were amplitude discriminated by Schmitt trigger comparators. During analysis, the $x$ and $y$ light position coordinates and neural spike data (Schmitt pulses) were sampled at a rate of $60 \mathrm{~Hz}$ and $4.0 \mathrm{kHz}$, respectively, and stored on disk in parallel time-stamped arrays (PDP-11/34, Digital Equipment Corporation, Maynard, MA).

From the stored time-synchronized spike and $x-y$ position data, it was possible to construct maps of movement trajectories, time-in-location, and spike firing density for any location on the platform. Sixbit resolution of the video record was employed yielding a pixel size of approximately $1.0 \mathrm{~cm}^{2}$ on the platform. Three basic types of maps were utilized: the traversal pattern of the animal on the platform during 7$10 \mathrm{~min}$ recording sessions (traversal), location-specific neural spike firing (firing density map), and firing density normalized by time spent in each location (firing rate map). Measurements derived from these maps in- 


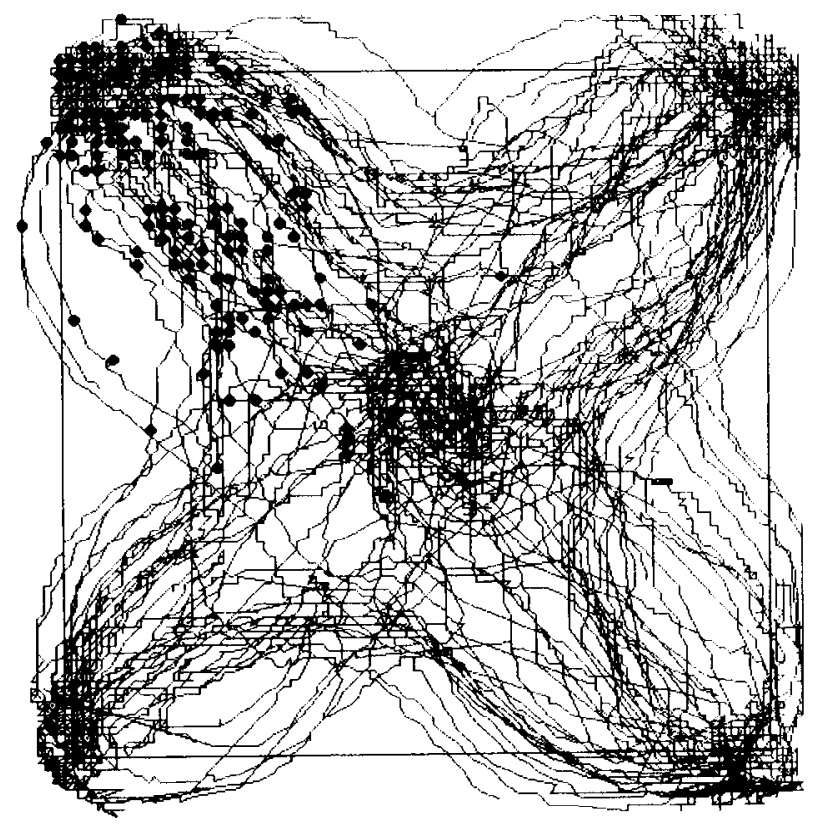

TRAVERSAL \& FIRING

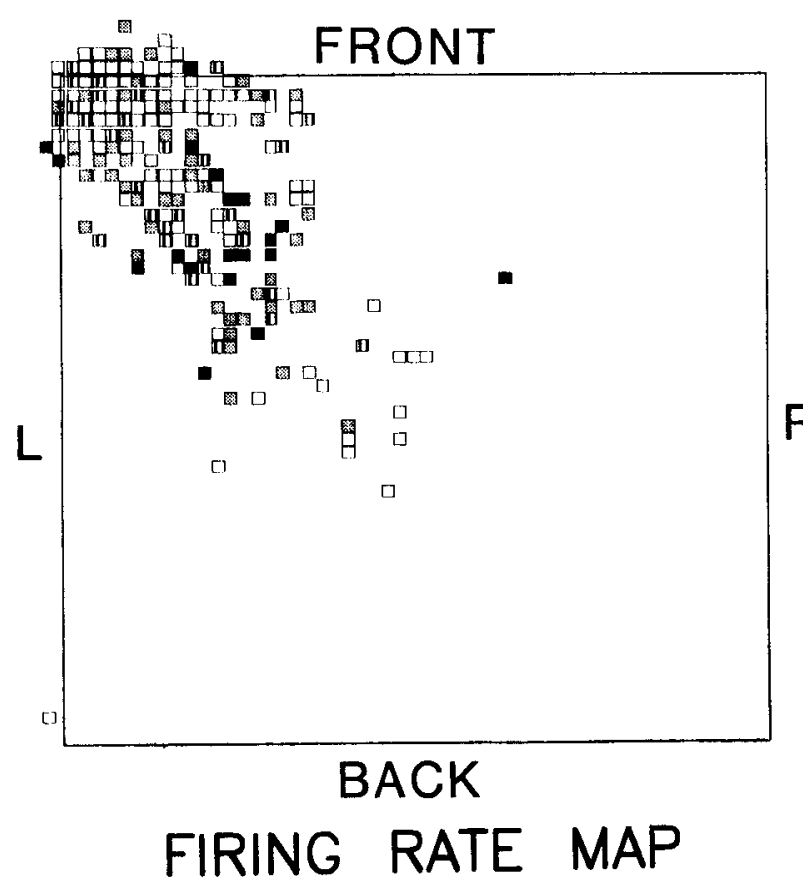

Figure 2. Two maps generated from spike and position data recorded from a complex spike cell in CA1, Left. Traversal map shows the traversal pattern of the animal as it visited the 5 water cups on the platform during a typical 8 min session. The position of spike firing locations are superimposed on the traversal trajectories as dots. Right, Firing rate map. The density firing map shown at left was normalized for time-in-location. Small squares (pixels) delineate an area $1.0 \mathrm{~cm}^{2}$ on the platform. The number of spike occurrences within a pixel(s) was divided by the total time spent at that pixel to yield rate in spikes/pixel/sec. Key: Open pixels represent $0.1-1.9$ spikes/sec, striped pixels represent $2.0-3.9$ spikes/sec, stippled (shaded) pixels represent 4.0-5.9 spikes/sec, and filled pixels represent $\geq 6$ spikes/sec.

cluded spike occurrence determined before and after crossing into particular locations and directional vectors derived from the sequential comparison of the location of successive spike occurrences.

Place fields were characterized by an algorithm similar to that described by Muller et al. (1987) which searched for clusters of pixels having a firing density greater than 2 spikes/pixel. The algorithm excluded all pixels with cell firing below this threshold, then noted the presence of spikes satisfying this criterion in each of the neighboring pixels up to 4 pixels removed on each side. If one or more neighboring pixels satisfied the spike firing criteria ( $\geq 2$ spikes/pixel), the field was expanded to include that pixel. Each added pixel was then tested for the presence of neighboring pixels exceeding the firing criterion and so on until no more neighboring pixels were encountered that met the criteria. Boundaries of the place field were then established by constructing a rectangle formed by the intersection of orthogonal lines connecting the minimum and maximum $x$ and $y$ coordinates of pixels in the field satisfying the 2 spikes/pixel firing criterion. The center of the place field was defined as the area with the highest firing density within the field boundaries. Statistical analyses of place field measurements were performed using PC SAS STAT (SAS Institute, Cary, NC) on a Zenith Z-248 computer (Zenith Data Systems, St. Joseph, MI).

\section{Results}

Iocation-specific firing of hippocampal place cells

The results of a typical recording session are shown in Figure 2. The left panel (traversal and firing) is the traversal map of the video-tracked movements about the platform as the animal visited each of the 5 cup locations. The time-in-location at each cup was greater than in the other areas on the platform because of the animal's tendency to check each cup for water delivered on a random basis. Supcrimposed on the traversal map is the firing density map showing the location of spike occurrences (dots) for the session. The right panel (firing rate map) shows firing density adjusted for time-in-location (traversal) providing the firing rate (spikes/sec) at each location in the field. For the cell in Figure 2 the place field was located in the front left corner of the platform. Note that firing was confincd to this location, even though the animal visited other cups on the platform as often as the one in which the cell fired (see traversal map). Since the firing rate map normalizes firing density for differences in time-in-location, the rate maps could be directly compared for different cells.

\section{Control of place field firing by off-platform cues}

Control of place field firing by environmental cues was shown by changing the position of the large cue card mounted on one wall of the enclosure. The results of one such experiment in which the place field in the back right corner of the platform shifted to the back left corner when the card was moved to the left wall of the enclosure are shown in Figure 3. The field retained the same relative position to the cue card even though the card was located on the left, rather than the back, wall of the enclosure. Replacement of the card to its original location (back wall) returned the place field to its initial position on the platform (Fig. 3, lower). Changes in card location produced significant changes in all 12 fields ( 6 animals) tested as determined by comparing the percentage of firing in each of 9 equal divisions of the platform before and after the card was moved $\left(\chi^{2}\right.$ range for all cells: $25.3-35.7 ; p<0.001)$.

\section{Control of place cell firing by distance from field center}

O'Keefe and Nadel (1978) postulated that place cell firing should increase as the animal moved toward the center of the place field. Muller et al. (1987) found that firing density was not a simple function of distance from a given point within the field. We examined this trend by calculating the number of spikes 

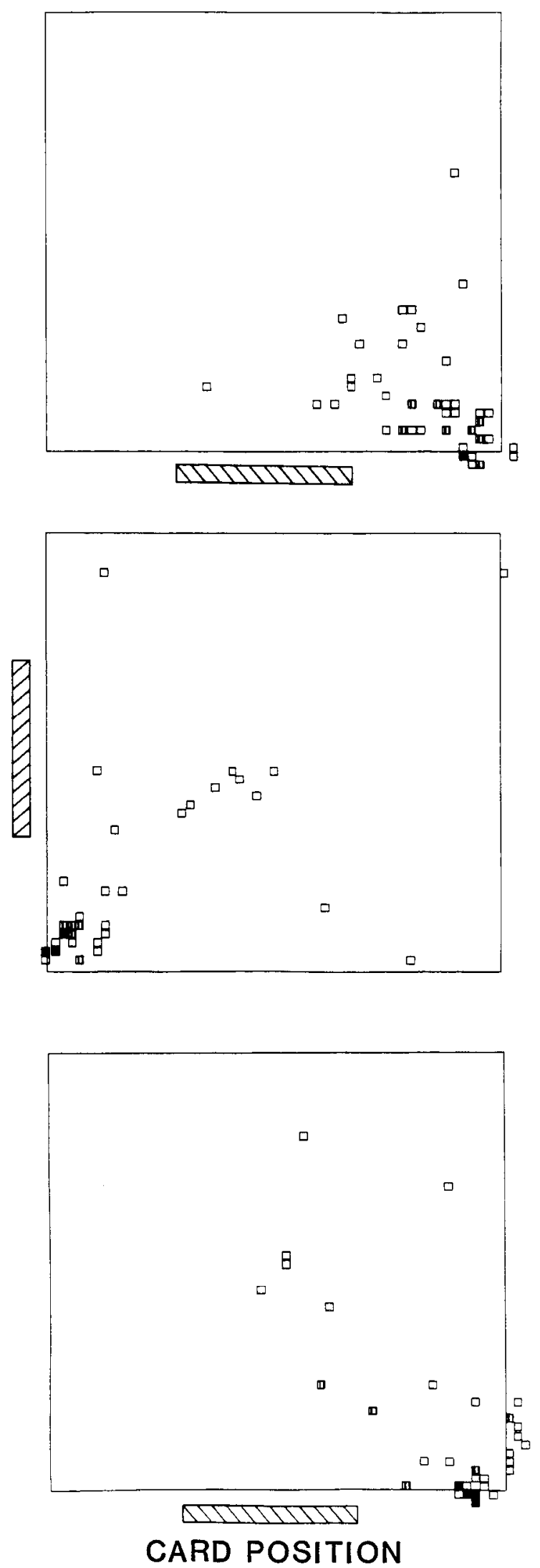

Figure 3. Demonstration of control of place field firing by off-platform cues. Top, Firing rate map showing place field of a complex spike cell recorded in CA1 in back right corner of the platform (see Fig. 2 for standard platform orientation). The crosshatched rectangle indicates location of white cue card on the back wall that acted as a polarizing stimulus to the otherwise black homogeneous curtained enclosure. Mid-

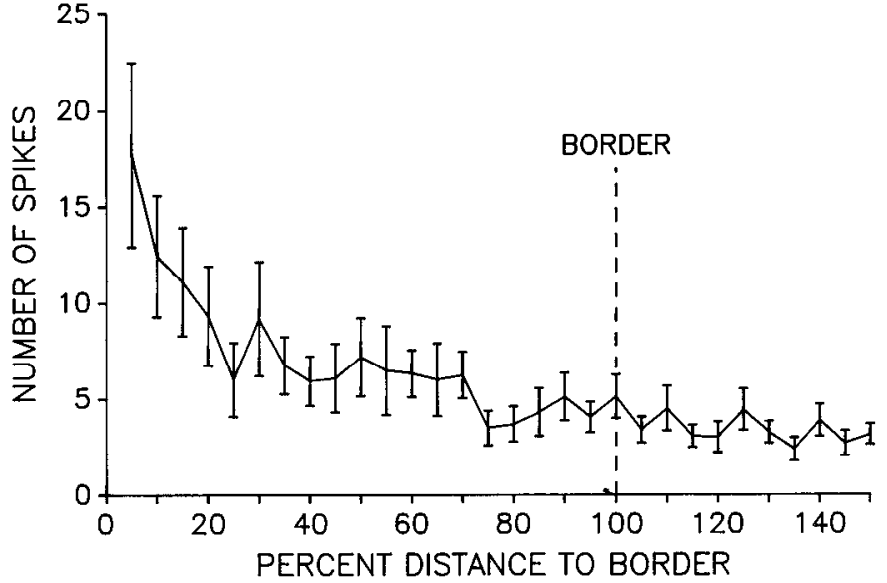

Figure 4. Mean spike firing density in relation to percent distance from the center of the place field to the border. Cell firing was measured at $1 \mathrm{~cm}$ (1 pixel) increments from the center of the field as defined by highest spike density and normalized for distance to the border of each field as defined by the algorithm. Each point represents the mean \pm SEM for 41 cells.

within successive $1.0 \mathrm{~cm}$ increments extending outward in all directions from the point of highest firing density to the border of each field (defined by the algorithm, see Materials and Methods). The results shown in Figure 4 indicate firing density decreased monotonically as a function of distance to the border. The average distance over which this change in firing density occurred was $22 \mathrm{~cm}$. Thus, percentage of distance to the border from the point of highest firing density was an accurate predictor of the distribution of spikes within the field.

\section{Boundaries of place fields}

Another factor that influenced firing of place cells was the existence of "borders" or "edges" where increases in firing occurred adjacent to regions of low firing (Fig. 5, left). The algorithm detcrmincd place field borders corresponding to specific $x$ and $y$ locations on the platform in which a firing criterion of 2 spikes/pixel for any adjacent 4 pixels was no longer satisfied. Total firing was separated into 5 categories, including (1) 0.5 $\mathrm{sec}$ before entering and after exiting the field, (2) $0.5 \mathrm{sec}$ after entering and before leaving the field, and (3) at any other time while in the field (Fig. 5, middle). The largest proportion of cell firing occurred at least $0.5 \mathrm{sec}$ after entry or $0.5 \mathrm{sec}$ before leaving the field (mean in field, $39.25 \pm 2.74 \%$ ). However, this large proportion reflects firing that may have occurred over a longer time period than the other 4 categories. The percentage of total firing that occurred within $0.5 \mathrm{sec}$ after crossing a border to enter the field (mean entry, $20.10 \pm 1.55 \%$ ) was significantly increased over that measured $0.5 \mathrm{sec}$ before entry (mean before, $8.63 \pm$ $\left.1.10 \% ; F_{(4.360)}=22.89 ; p<0.0001\right)$. The mean percentage of firing $0.5 \mathrm{sec}$ before leaving the place field (mean exit, $19.90 \pm$ $1.32 \%$ ) was also significantly increased from the percentage fir-

dle, Rotation of the place field (firing map) to the back left corner when the cue card was moved to the left wall of enclosure. Note that the field maintains its original position relative to card location after rotation. Bottom, Restoration of the place field to the back right corner when cue card was returned to original location shown above (top). 

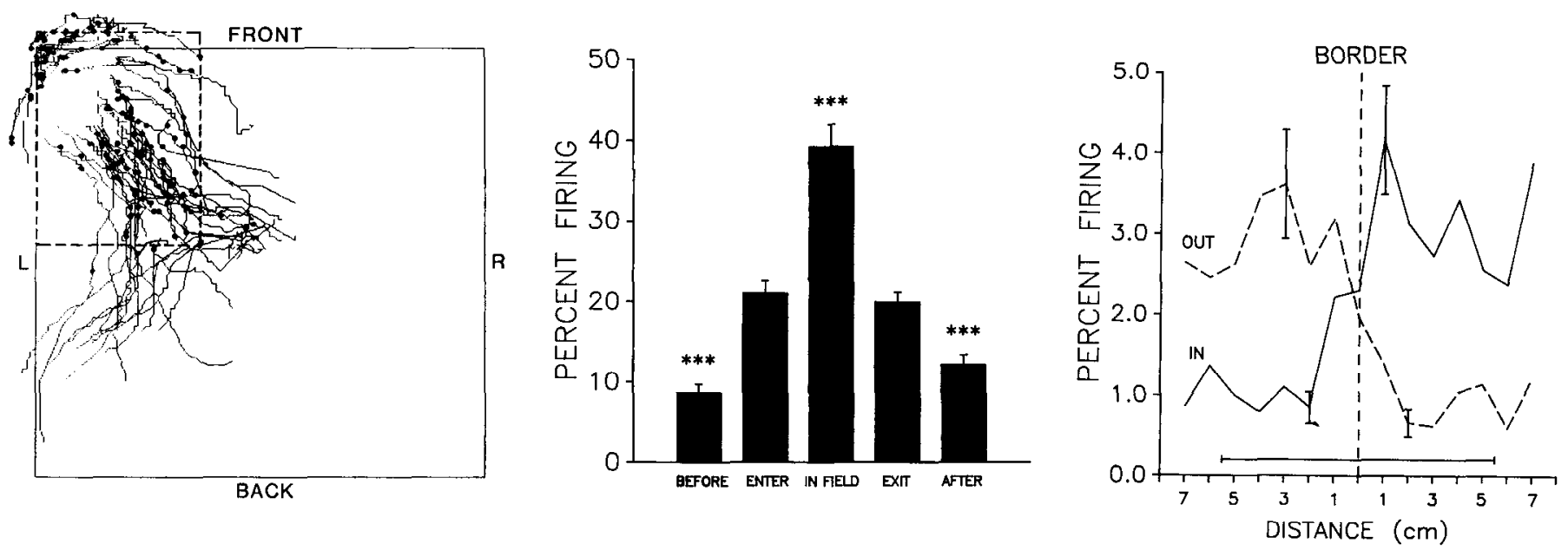

Figure 5. Demonstration of place cell boundaries. Left, Traversal and firing density map shows example of place field and associated boundaries (dashed line) calculated from the $x$ and $y$ coordinates of the minimum and maximum pixels satisfying the 2 spikes/pixel criteria for inclusion in the place field. The irregular lines show traversals for $0.5 \mathrm{sec}$ before and after crossing the border for all entries into the field. Dots indicate the location of spikes. Middle, Histogram showing mean $( \pm \mathrm{SEM})$ percent firing $0.5 \mathrm{sec}$ before and after crossing of the boundary on entry and exit from the field, as well as all other firing occurring in the field (In Field). Means were calculated for 47 cell fields. Asterisks (***) indicate significant differences between adjacent bars $(p<0.001)$. Right. Graph showing mean percent firing density at locations $0-8 \mathrm{~cm}$ before (left) and after $($ right $)$ crossing the border (center dashed line) of the place field. Entry into the field is represented by the solid line (IN). Exit from the field is represented by the dashed line (OUT). Error bars indicate maximum and minimum SEM. The horizontal bar represents the mean distance (5.5 $\mathrm{cm})$ equivalent to $0.5 \mathrm{sec}$ before and after border crossing as shown in middle panel.

ing $0.5 \mathrm{sec}$ after exiting the field (mean after, $12.15 \pm 1.22 \%$; $\left.F_{(4,360)}=10.45 ; p<0.001\right)$.

The relationship between border crossing and firing was further examined by calculating the percentage of firing corresponding to when the animal either entered or exited the field. Figure 5(right) shows distinct changes in percentage firing as the border was crossed, with respective increases and decreases as the animal entered (in) and exited (out) the field. When the animal crossed the border to enter the field, there was a change from a maintained level of $1.0-1.5 \%$ firing to above $2.3 \%$ of the total firing. A decrease in firing of the same magnitude was associated with the animal crossing the border to exit the field. Differences between in and out of field firing were the same as in Figure 5(middle). Specific contrasts between means in Figure 5 (right) revealed significant differences only at the border for inward and outward movements [Inward: $2 \mathrm{~cm}$ before vs $1 \mathrm{~cm}$ after (SEMs), $F_{(1,80)}=31.91 ; p<0.0001$; Outward: $3 \mathrm{~cm}$ before vs $2 \mathrm{~cm}$ after (SEMs), $\left.F_{(1,80)}=27.01 ; p<0.0001\right]$.

Further analyses of place cells for directional biases were performed on cells meeting a criteria of 20 or more inward and outward trajectories that crossed the border of the place field $(n=27)$. Results showed that although the mean number of total trajectories associated with entering and exiling fields were equal ( $28.7 \pm 2.07$ and $28.8 \pm 2.09$, respectively), $10 \%$ more inward-directed trajectories were associated with spike occurrence (mean, $34 \pm 0.04 \%$ ) than outward (mean, $24 \pm$ $0.03 \%)$ trajectories $\left(t_{\varsigma_{52}}=2.03 ; p<0.05\right)$. This increased tendency toward spike firing on entering the field was examined for individual cells and is illustrated in Table 1. Fourteen cells had more inward than outward trajectories with spike occurrences, while only 1 cell had more outward than inward trajectories with spike occurrences. The remaining 12 cells showed no bias for firing associated with inward or outward trajectories. In contrast, there were equal numbers of cells that showed a bias in number of spikes per trajectory for inward ( 7 cells) and for outward ( 7 cells) trajectories. There was also no difference in the number of cells that showed a bias for trajectories with 3 or more spike occurrences ( 8 cells inward, 8 cells outward). Thus a tendency toward greater discharge on entering rather than exiting a field was exhibited by a disproportionate number of cells with one or more spikes per trajectory, while equal numbers of cells showed inward and outward biases in the mean number of spikes per trajectory and in percentage of trajectories with 3 or more spikes.

\section{Relation of within-field firing to movement trajectory}

The relationship between spike firing and the traversal pattern of the animal in the field (Figs. 2,5) indicated movement trajectories within the place field closely matched the pattern of spike occurrences. Place cell firing could represent calculation of the movement trajectory from one place to another on the platform. If such were the case, spike occurrence should be correlated more with the position of the animal at some future time (resulting in constriction of the place field) than the position of the animal at the instant of spike occurrence. This hypothesis

Table 1. Number of cells showing biases in spike firing upon entering or leaving the place field

\begin{tabular}{lcl} 
& & $\begin{array}{l}\text { Cells } \\
\text { with }\end{array}$ \\
& $\begin{array}{l}\text { Cells with } \\
\text { In }>\text { Out }\end{array}$ & $\begin{array}{l}\text { Out } \\
\text { In }\end{array}$ \\
\hline Trajectories with 1 or more spikes & $14^{b}$ & 1 \\
Number of spikes per trajectory & 7 & 7 \\
Trajectories with 3 or more spikes & 8 & 8 \\
\hline
\end{tabular}

"In > Out: More trajectories or spikes/trajectory entering the place field than exiting the field. Out > In: More trajectories or spikes/trajectory exiting the place ficld than entering the field.

${ }^{b} \chi^{2}=11.3, p<0.001$. 

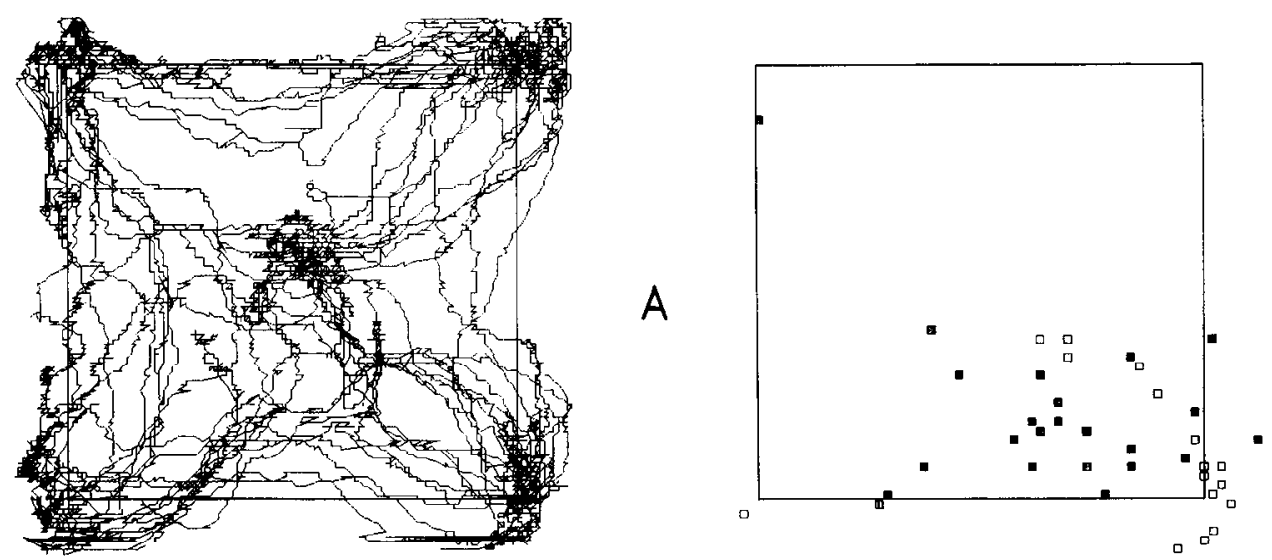

Figure 6. Traversal and firing maps showing the effect of a barrier on place field firing. $A$. Initial recording revealed a place field located in the back right corner of the platform. $B$, A clear Plexiglas barrier forming a right angle 25 $\mathrm{cm}$ high and $25 \mathrm{~cm}$ on each side (solid dark lines) was placed restricting traversal into the place field. The location of the place field was still visited by the rat, but cell firing was decreased. $C$, Place field firing was restored when the barrier was removed.
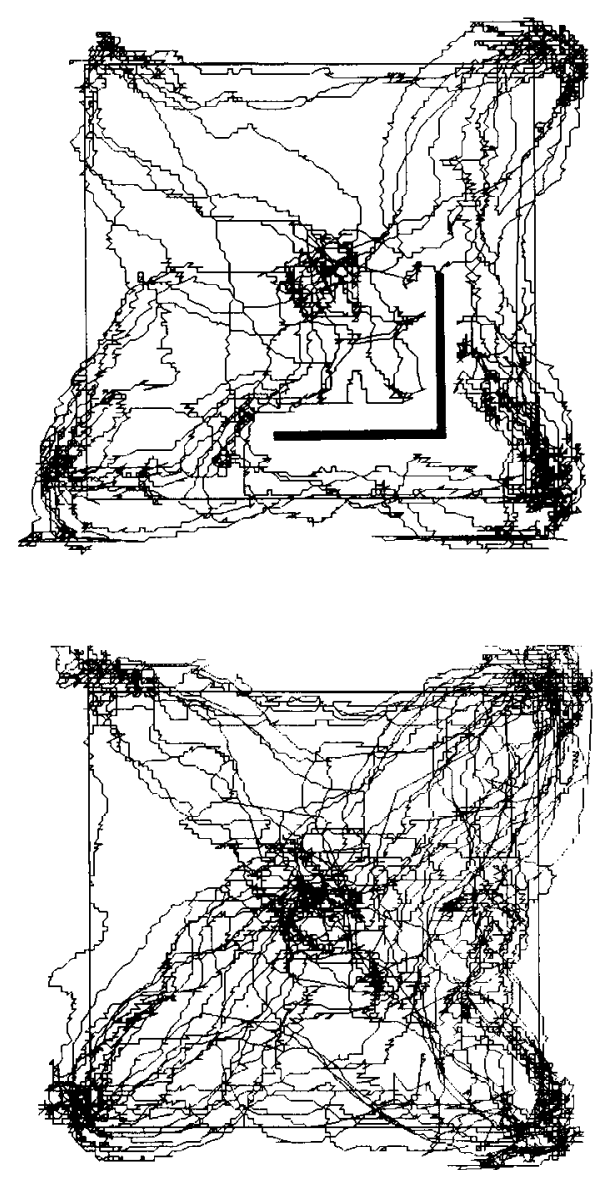

TRAVERSAL MAP

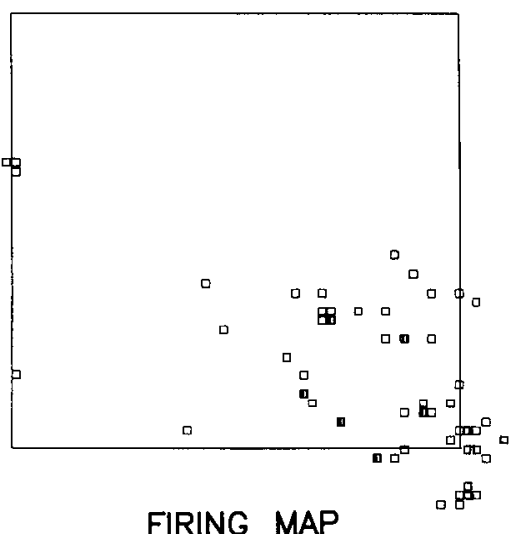

FIRING MAP was advanced by Muller and Kubie (1986) after observing that place fields recorded in their apparatus were maximally constricted if spike firing locations were "time-shifted" forward to the animal's position $167 \mathrm{msec}$ after spike occurrence. This suggests the spatial information associated with place cell firing represented an anticipated position rather than the present position of the animal.

A time-shift analysis of firing density and field size was performed on 60 individual cell fields in the present study. The data were time-shifted in $0.1 \mathrm{sec}$ increments forward and backward over a total span of $3.0 \mathrm{sec}$. There was a near symmetric constriction of average field size (area) from 550 to $200 \mathrm{~cm}^{2}$ as the time-shift converged forward or backward in time to the instant of spike occurrence (zero time-shift), with the smallest fields associated with a zero time-shift. No differences with respect to place field size were seen between past and future timeshifts. Time-shifts calculated on other measures of firing tendency confirmed this as well, including average number of pixels in the field and, most convincingly, distance of each spike from the point of highest density in the field (a direct measure of the degree of expansion and contraction of the field). The time-shift analysis indicated that fields were changed in a manner expected if the animal were running at constant speed on the platform and did not support the conclusion that firing reflected calcu- 

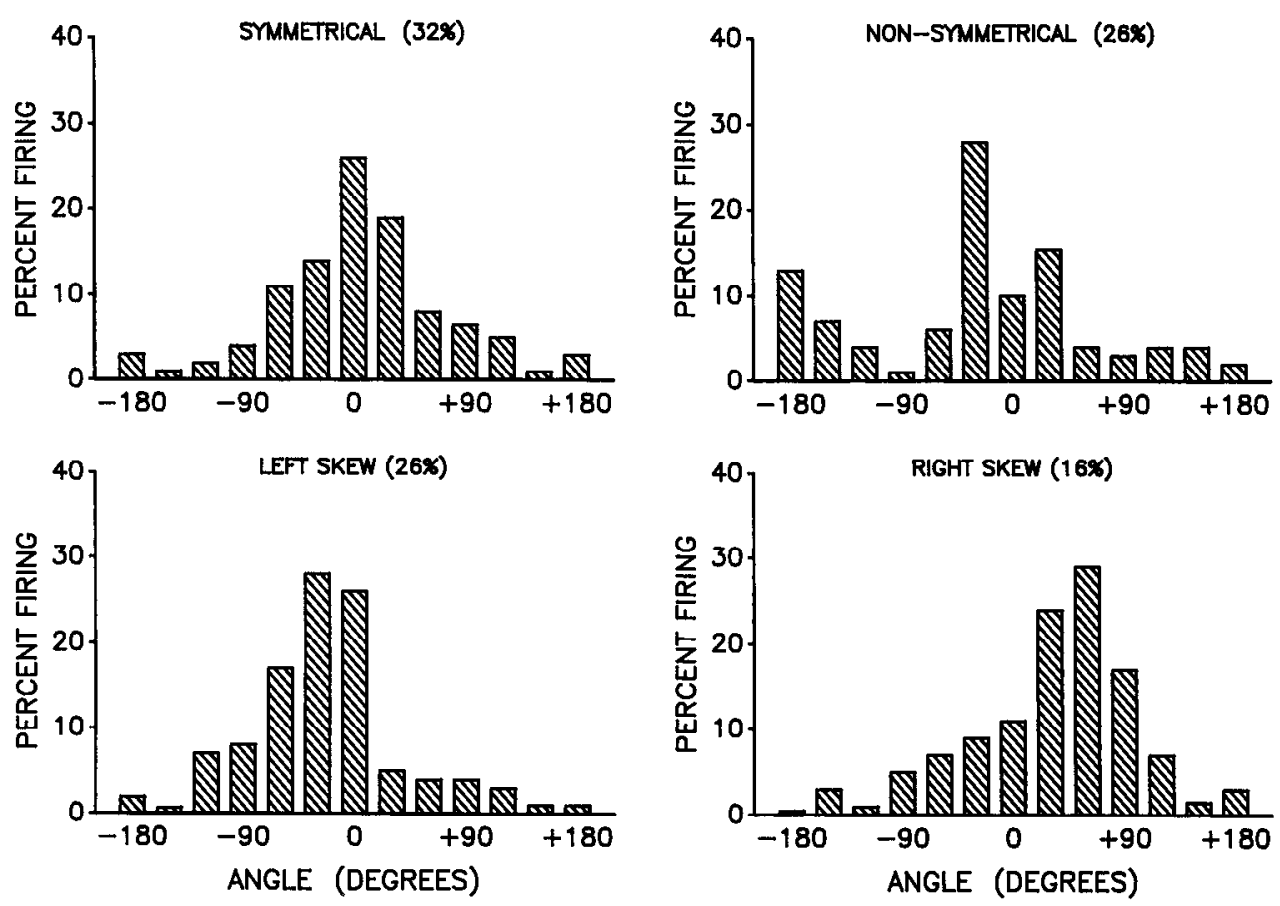

Figure 7. Distribution of deviation
angles for successive spikes in 4 indi-
vidual cells representing the 4 different
types of relative directional firing be-
tween spikes. Symmetrical, The devia-
tion angle distribution for this cell type
was similar for the total population of
cells. Non-symmetrical, The distribu-
tion of deviation angles for this cell type
exhibited neither symmetry nor uni-
formity. Left and Right Skew, Devia-
tion angle distributions were biased
toward left $(-)$ or right $(+)$ deviation
angles.

lation or anticipation of movement to another location in the field.

\section{Effects of barriers on place field firing}

Muller and Kubie (1987) showed that strategically placed barriers altered place cell firing if the barrier interrupted the projected path of movement within the field. A similar result was demonstrated in this study for 6 place cells recorded in 3 different animals. Barriers were placed on the platform to block traversal into established place fields as shown in Figure 6. The barrier effectively eliminated spike occurrence within the field even though the traversal map indicated that the time spent in the original field location was equivalent. The placement of the barrier presumably reduced place cell firing because the animal could no longer use the same trajectory to traverse the place field. The introduction of barriers, however, had unpredictable effects on different place cells. In some cases, firing was eliminated completely; in others, firing was increased in a different location on the platform; and in still others, firing on the proximal side of the barrier was unaffected but was eliminated on the distal side of the barrier. The basis for the divergent effects of barriers on place cell firing is not known; however, Muller and Kubie (1987) reported similar inconsistent results.

\section{Directional analysis of place cell firing}

Another feature that might have influenced firing within the field was the direction the animal was moving as it traversed the place field (Breese et al., 1987). Relative and absolute directional sensitivity was calculated for within-field firing utilizing deviation angles of vectors constructed by linking successive spike occurrences. These measures did not utilize data generated by the animal's traversal between spikes but only the location of each spike occurrence. For relative directional specificity, a vector formed by connecting the second to the third of 3 successive spikes was compared with a vector connecting the first and second spikes in the series. The angle formed by the dif- ferences in polar coordinates between the 2 vectors established the deviation angle in degrees from the prior direction as determined by the first 2 spikes. Deviation angles were calculated for successive spikes in the field meeting a rate criteria of 2 spikes/sec and summed into $30^{\circ}$ categories. A deviation angle of $180^{\circ}$ represented a spike that occurred in a direction exactly opposite the previous 2 spike occurrences. Deviations of $\pm 90^{\circ}$ represented cell firings orthogonal to the 2 previous spikes. This calculation reveals the relationship of cell firing to the direction the animal is heading and indicates whether cells fire more or less when there are deviations from that direction.

The results of this calculation for 35 cells showed most deviation angles were within $\pm 90^{\circ}$ of the directional vector connecting the previous 2 spikes and that the total number of angles summed over all cells was normally distributed around $0^{\circ}$. However, deviation angle distributions for individual cells were not necessarily normally distributed and could be categorized into the 4 types shown in Figure 7 . Cells exhibiting nearly symmetric distributions of deviation angles represented $32 \%$ of the total cells sampled. Two other cell types showed "skewed" or "distorted" distributions: $26 \%$ were skewed to the left and $16 \%$ were skewed to the right. The final category had nonsymmetric (nonuniform) distributions, and these comprised $26 \%$ of the total number of cells.

In order to determine whether cell firing demonstrated absolute directional sensitivity, the vectors formed between each successive spike occurrence meeting the 2 spikes/sec criteria were combined with reference to fixed locations on the platform and enclosure. The vectors were summed into $30^{\circ}$ categories and were displayed as polar coordinates, with the center representing the animal's position on the platform at the first spike occurrence and the vector representing the absolute direction traversed prior to the next spike. The magnitude of firing in any given direction in terms of percentage of total spikes is indicated by the length of each vector. This is shown for a single place cell in Figure $8 A$ (direction) and for the total population of cells 
A

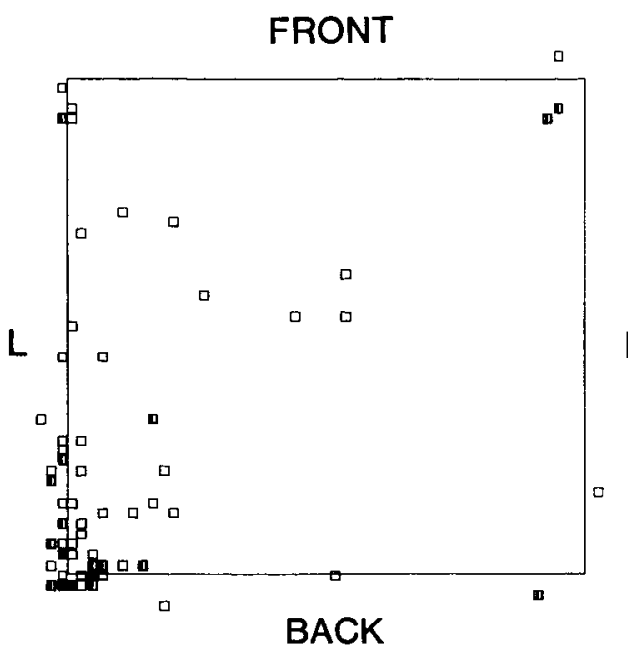

FIRING MAP

FRONT

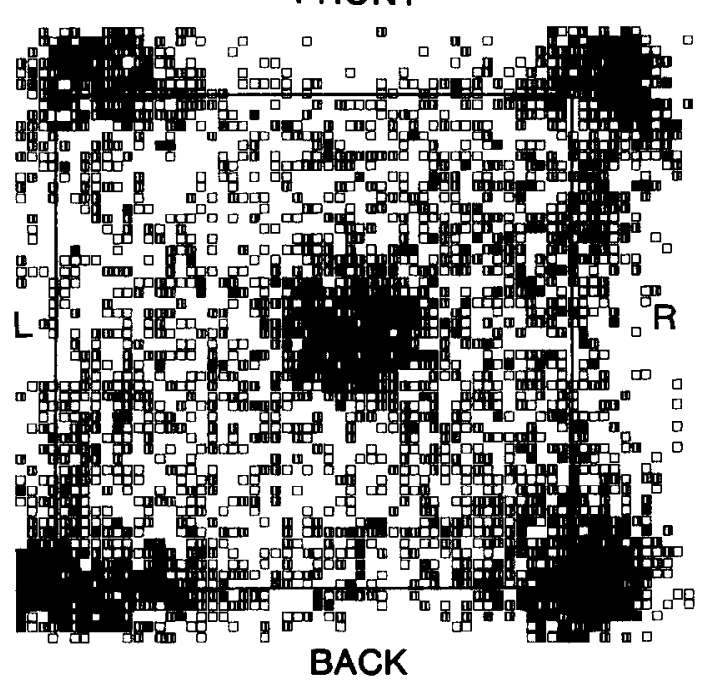

FRONT

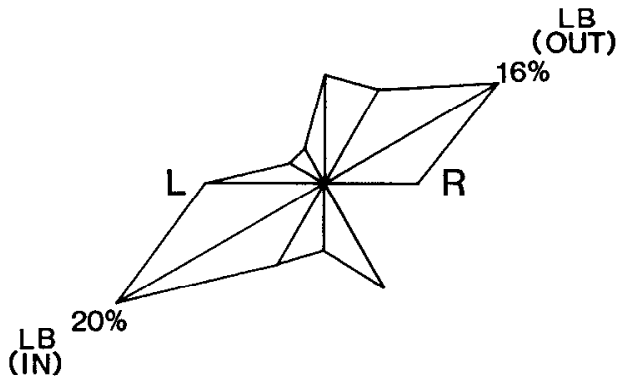

BACK

DIRECTION

FRONT

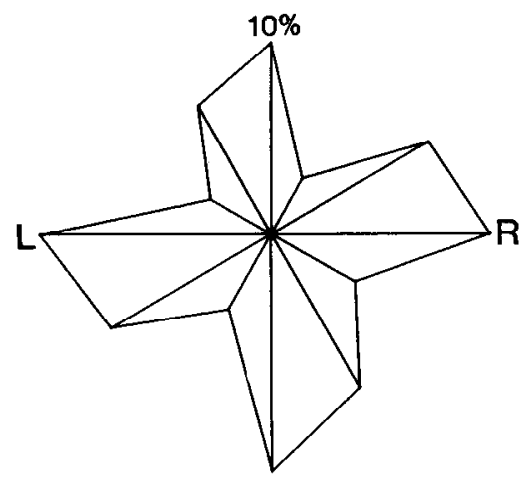

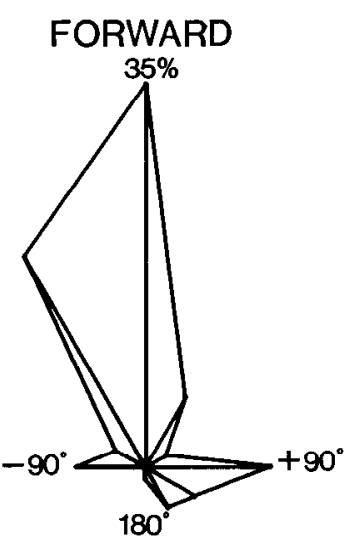

RELATIVE

\section{FORWARD}

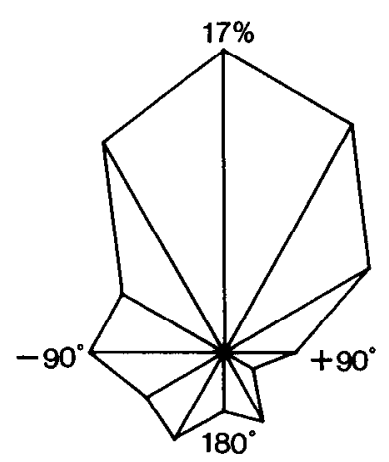

Figure 8. Directional features of place cell firing. A, Absolute and relative directional firing of a left skew cell. Firing Map, Firing rate map illustrates the back left location of a single place field. Direction, The directional polar histogram has the same orientation as the platform and shows the percentage of the total firing as polar vectors (summed into $30^{\circ}$ intervals). The center point of the polar histogram corresponds to the position at the time of spike occurrence with the vector pointing in the absolute direction of the next spike. The cell fired maximally when the animal was headed on a diagonal trajectory which represented traversal into or out of the place field (Firing Map). Relative, The relative direction polar histogram shows the cell firing deviation angles indicating a prominent left skew bias, with the majority of spikes associated with vectors in the $0^{\circ}$ to $-45^{\circ}$ category relative to forward movement of the animal. $B$, Mean relative and absolute directional firing tendencies for all cells. Firing Map, Composite firing map constructed from 35 different place fields. Direction, Same as in $A$ except plot includes all 35 cells. The highest mean percentage of directional firing was contributed by vectors which indicated firing parallel to the sides of the platform. This was the result of traversal patterns into and out of the corners of the platform. Relative, Same as in 4 except plotted as mean percent firing for 35 cells. Note majority of relative directional firing occurs between $\pm 30^{\circ}$ relative to forward movement of the animal.

in Figure $8 B$ (direction). The cell shown in Figure $8 A$ (firing map) exhibited a directional bias in 2 major directions that corresponded to entering and leaving the left back corner field on a diagonal trajectory. The relative directional firing of the same cell is also shown in polar coordinates (Fig. $8 \mathrm{~A}$, relative), indicating a predominant "left skew" (i.e., left turn) with respect to the direction signaled by spike occurrences.

In Figure $8 B$ the absolute and relative directional vectors of
35 individual cells were averaged, and a composite firing map of their respective place fields on the platform was constructed (Fig. $8 B$, firing map). There was an even distribution of the 35 place fields across the 5 water cup locations. The polar plot of mean absolute directional vectors reflected no discernible directional bias (Fig. $8 B$, direction), showing that all 5 water cup locations on the platform contained place fields (Fig. $8 B$, firing map). The polar plot of mean relative directional firing is illus- 
trated for all cells in Figure $8 B$ (relative), and it indicates a narrow range of deviations from prior spike occurrences restricted primarily to within $\pm 60^{\circ}$ of the vector pointing straight forward. The symmetry of the relative vector distribution reflects the sum of the 4 different firing tendencies illustrated by the cell types seen in Figure 7.

\section{Plasticity of place cell firing}

The majority of place fields observed on the platform were associated with specific water cup locations, even though the animal traversed all 5 cup locations (see Fig. $8 B$, firing map). We attempted to manipulate the significance of particular cup locations by selectively baiting a cup at a different location on the platform from that of the place field. One such experiment is shown in Figure 9. The upper panel (Fig. 9A) represents a typical field (traversal and firing map) when all 5 cup locations were randomly baited (crosses), 1 cup every $30 \mathrm{sec}$. Firing was localized to the back right corner and edge of the platform. The middle panel (Fig. 9B) depicts the recording session following selective baiting of the cup in the front left corner. Two changes were apparent: the place field was shifted to the location of the selectively baited cup, and no firing occurred in the location of the original place field, even though the traversal map showed a similar number of visits to the original location. The lower panel (Fig. 9C) shows a subsequent recording session after selective baiting was shifted to yet another (back left) cup location. Once again, the field was shifted to the baited cup and firing was eliminated in the previous field. The traversal map was more restricted in this case to the selectively baited cup, although there were still frequent visits to the location of the previous place field (Fig. 9B). The same place cell therefore exhibited shifts to 2 different locations without overlap with any of the prior fields. A total of 47 place cells ( 8 animals) were subjected to the selective baiting procedure; 40 showed significant shifts of the location of the place field as indicated by significantly altered firing density in different areas of the platform $\left(\chi^{2}\right.$ range $=20.5-225.2 ; p<0.01$ ).

In some cases, return to the original random baiting procedure (all 5 cups) caused changes in firing that were indicative of a return to the original field location. Figure 10 gives an example of a partial reestablishment of the place field following a return to the original random baiting procedurc (Fig. 10, $A, C$ ). Notc, however, that firing occurred in both the original and shifted field locations, as well as the areas in between along the edge of the platform.

The selective baiting procedure was very effective in most of the cases tested but did not always produce a shift in the place field. For instance, baiting a new location was not sufficient to insure a shift of the place field to that location if the cup in the original place field location remained baited. In other cases firing could be shifted to the new location, but the cell also continued to fire in the previous location. Frequently, firing also appeared between 2 baited locations, e.g., in the center of the platform along the diagonal between 2 opposite baited corners.

It was also possible to observe what appeared to be transitions in place cell firing during the selective baiting procedures. Figure $11, A, B$ illustrates a completed shift in place field to the center cup from an original field in the front left corner. The traversal map indicates a "spiral-type" approach pattern associated with entry into the center of the platform from each of the 4 corners which is mimicked by firing along those trajectories in the firing map. The lower panel (Fig. $11 C$ ) depicts the transition in firing following a shift in selective baiting to the back right cup. The traversal map shows the associated change in traversal pattern to that cup location. The firing map indicates a transition in firing between the center and back right positions on the platform which corresponded closely to the heavily traveled path between the 2 areas as shown on the traversal map. Firing that had been previously localized to the center cup "stretched" into the regions between the previously baited cup and the newly baited location (Fig. $11 \mathrm{C}$ ), indicating a possible transitory phase in which firing was distributed between the original and newly shifted locations.

Since place field locations could be shifted by the relatively simple procedure of selectively baiting a single location, it was important to determine the minimal time required for this transition. Figure 12 shows the results of a continuous session in which a change in field location resulted from a 15 min exposure to the selective baiting procedure. Eight minutes elapsed between the time the selective baiting procedure was initiated in Figure 124 and the beginning of the 7 min recording session shown in Figure 12B. The shift in the place field was therefore observed within $15 \mathrm{~min}$ after initiation of the selective baiting procedure. Figure $12 \mathrm{C}$ shows a second $7 \mathrm{~min}$ recording session that was continuous with the session in Figure $12 B$, indicating the stability of the shifted place field.

It was important to determine whether the shifted place fields following selective baiting were accompanied by differences in the basic parameters of place cell firing. Consequently, place cell activity was quantified by examining interspike distance, time, and velocity (distance/time) between spikes in the random baiting condition and after the field was shifted by selective baiting $(n=40)$. There were no differences between control and shifted fields in any of these measures. Comparison of the relative directional firing sensitivity of place cells before and after selective baiting of a particular cup revealed a significant main effect between the 2 groups $\left(F_{(12,351)}=2.55 ; p<0.003\right)$ which resulted from a significant increase in the frequency of directional vectors in the $0^{\circ}$ category (mean, $17.2 \pm 2.88 \%$, random, vs $29.2 \pm 2.69 \%$ baited; $\left.F_{(12,351)}=22.41 ; p<0.0001\right)$ and fewer directional vectors in the $> \pm 60^{\circ}$ categories. Thus, in the selective baiting condition, cell firing tended to deviate less from the direction signaled by previous spike occurrences.

\section{Discussion}

\section{Factors controlling within-field firing of place cells}

The propensity for complex spike cells in the hippocampus to exhibit place field firing has been demonstrated previously (see Olton et al., 1978; O’Keefe, 1979; Best and Ranck, 1982; Kubie and Ranck, 1983; McNaughton et al., 1983; Christian and Deadwyler, 1986). The results of this study have shown complex spike cells exhibit place cell activity of the following nature: (1) a decrease in firing density with distance from the center to border of the place field; $(2)$ borders or boundaries in the vicinity of which firing was significantly increased on entering and decreased on exiting from the place field; (3) significant firing biases of trajectories associated with entering versus exiting the field; (4) absolute directional firing tendencies, which reflected the angle of movement required to enter and exit a particular region of the platform; and (5) relative directional firing by place cells, which was represented by 4 different cell types-symmetric, nonsymmetric, and skewed right or left.

If place cell discharge within the field was determined strictly by the animal's position relative to fixed cues on or off the 

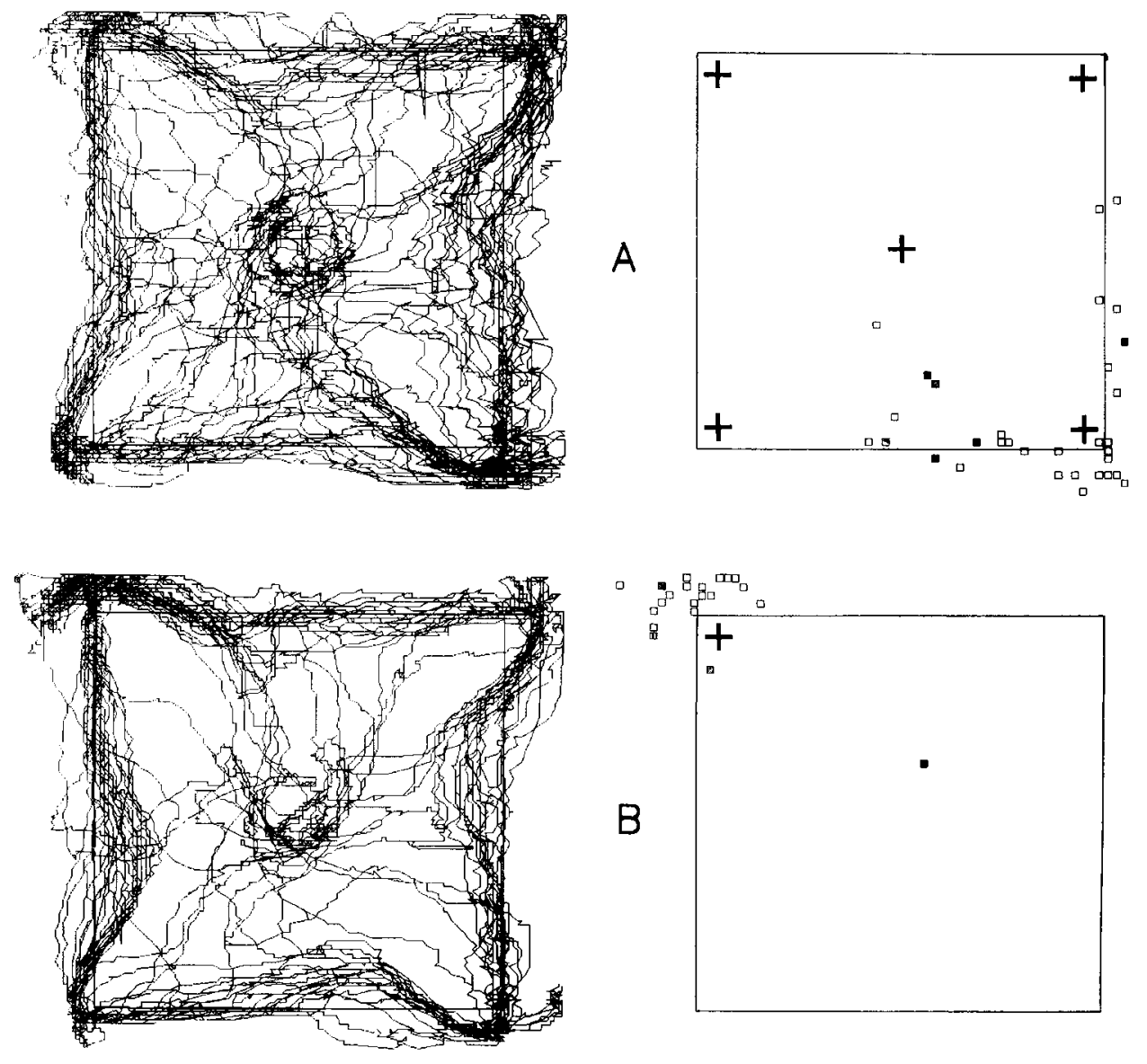

Figure 9. Traversal and firing maps showing place field shifts with selective baiting of a single cup after random baiting of all 5 cups. The location of baiting in all cases is represented by the crosses at the corners. $A$, Random baiting condition produced a place field diffusely localized to back right corner. $B$, Selective baiting of front left cup shifted the place field to that location. $C$, Selective baiting of back left cup shifted the location of the place field a second time, which was associated with a slight increase in traversal of that region.
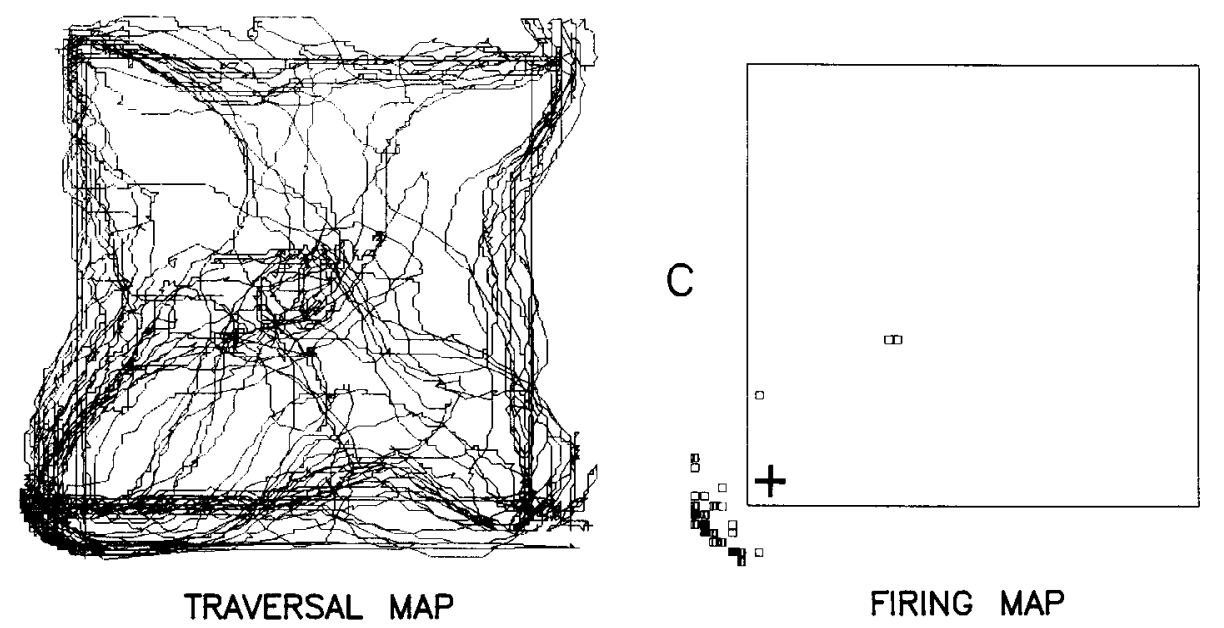

platform (Zipser, 1985, 1987), the angle of traversal through the place field relative to those cues would have determined the distribution of deviation angles for the cell. This was not the case, as analyses of absolute directional vectors of all spikes within place fields showed the 4 absolute directions of traversal were nearly equally represented. This was consistent with the fact that place fields tended to be distributed in all 5 cup locations on the platform (Fig. 8B, firing map). These analyses indicate place cell firing also occurs within a direction-specific (relative and absolute) framework defined largely by the location of the field. Since individual place fields had different absolute directional tendencies and could be controlled by manipulation of off-platform cues, firing of the place cell appeared to signal both relational and absolute spatial features of the environment. In addition, different types of place cells exhibited unique firing patterns with respect to maintenance of (symmetric cells) or deviation from (skewed cells) the current direction of movement. The interaction of both cell types would therefore provide complementary signals of deviations from a given movement trajectory. Further analyses of inward versus outward directed 

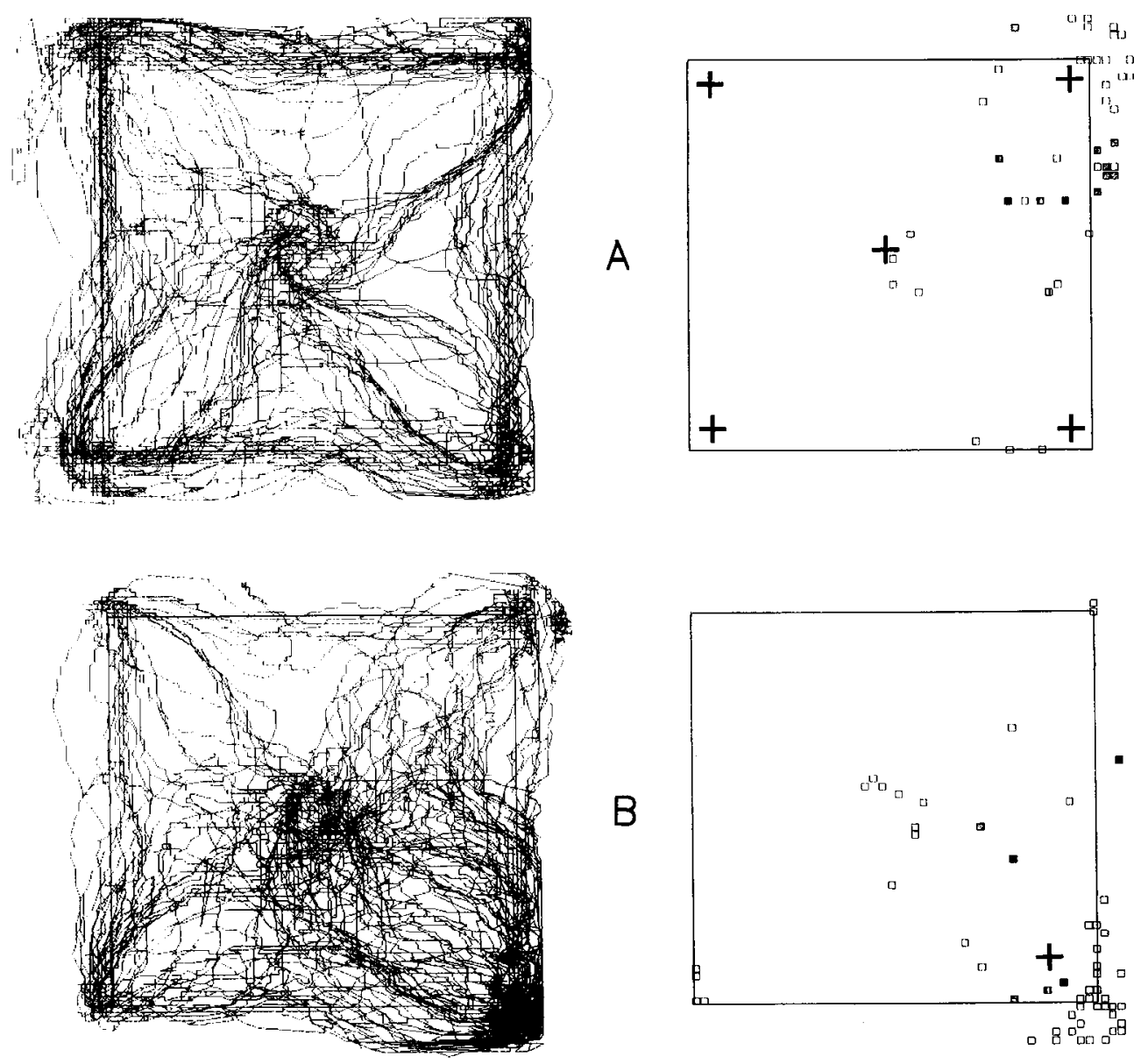

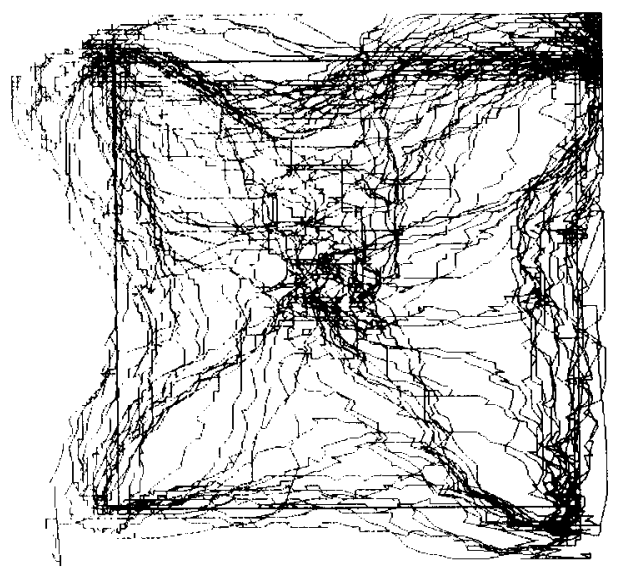

TRAVERSAL MAP

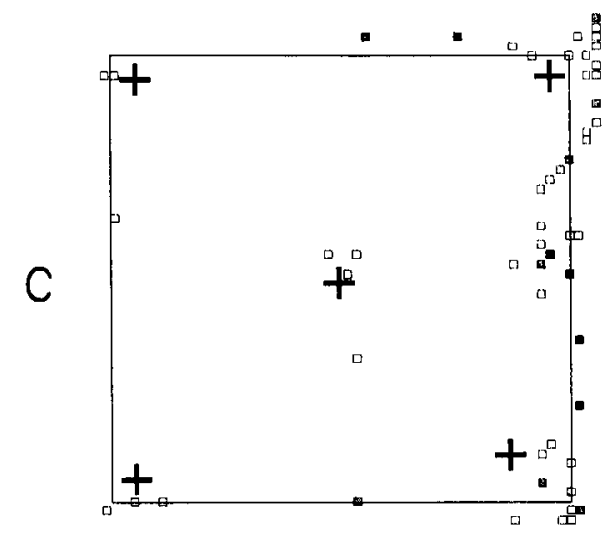

FIRING MAP
Figure 10. Effect of selective baiting followed by return to random baiting procedure. $A$, Initial random baiting condition revealed a diffuse place field in the front right corner of the platform. $B$, Selective baiting of the back right corner of the platform produced a shift in the place field to that location with little residual firing in the previous location. $C$, Return to the random baiting condition dissolved the place field in back right corner and produced firing distributed along the entire right edge of the platform, which included the location of both place fields. trajectories indicated a slight but significant bias for firing on trajectories associated with moving into versus moving out of the field (Table 1).

The absence of a time-shifted change in place field size or density indicates that spike occurrence signaled the current position of the animal and did not register a future (to be occupied) position as suggested by Muller and Kubie (1986). The failure to demonstrate a time-shift effect may have resulted from differences between the animal's movements in the Muller and Kubie (1987) testing chamber and the platform used in this study. If the animal stopped or even slowed significantly during traversal of the place field, it would produce a time-shift and a maximum constriction of the field size similar to that reported by Muller and Kubie (1986). Also, if the number of spikes within the field was not held constant during calculation of a time-shift (i.e., spikes were lost due to the fact that they were shifted out of the field border), the field size would also constrict at a time different from actual spike occurrence (producing a timeshift). From Muller and Kubie's (1986) description, it cannot be determined if either of these factors could have influenced 

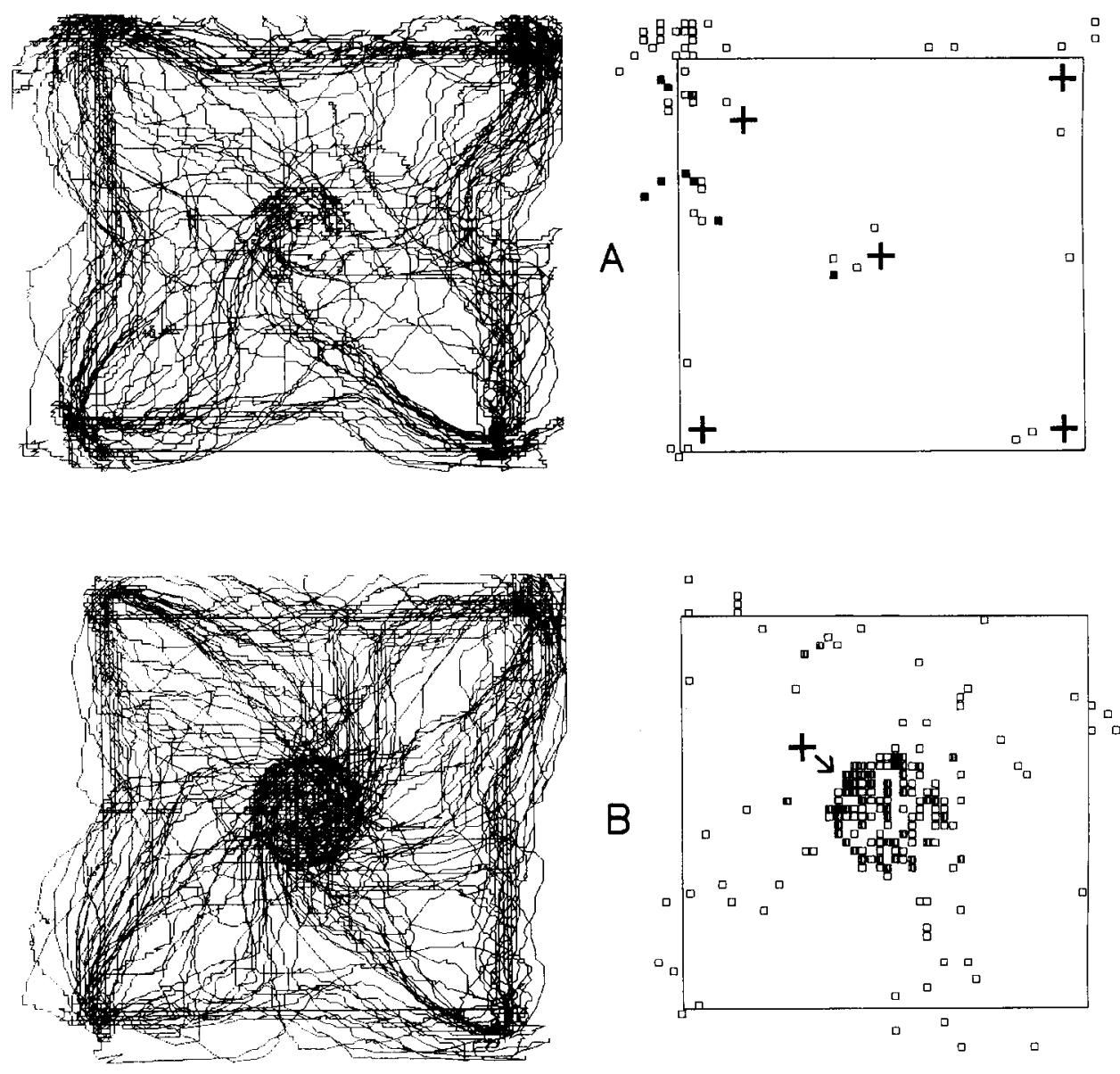

Figure 11. Transitory changes accompanying shifts in place fields. $A$, Random baiting condition revealed a place field in the front left corner of the platform with some firing at each of the other 4 locations. $B$, Following $20 \mathrm{~min}$ of selective baiting of the center cup, place field was shifted to the center with associated change in traversal pattern. $C$, Selective baiting of back right cup resulted in partial shift of firing to the vicinity of the back right corner of the platform, with residual firing in the center of the platform also present. Note tendency for firing to be distributed along the traversal patterns between the center and back right cups (Traversal Map).
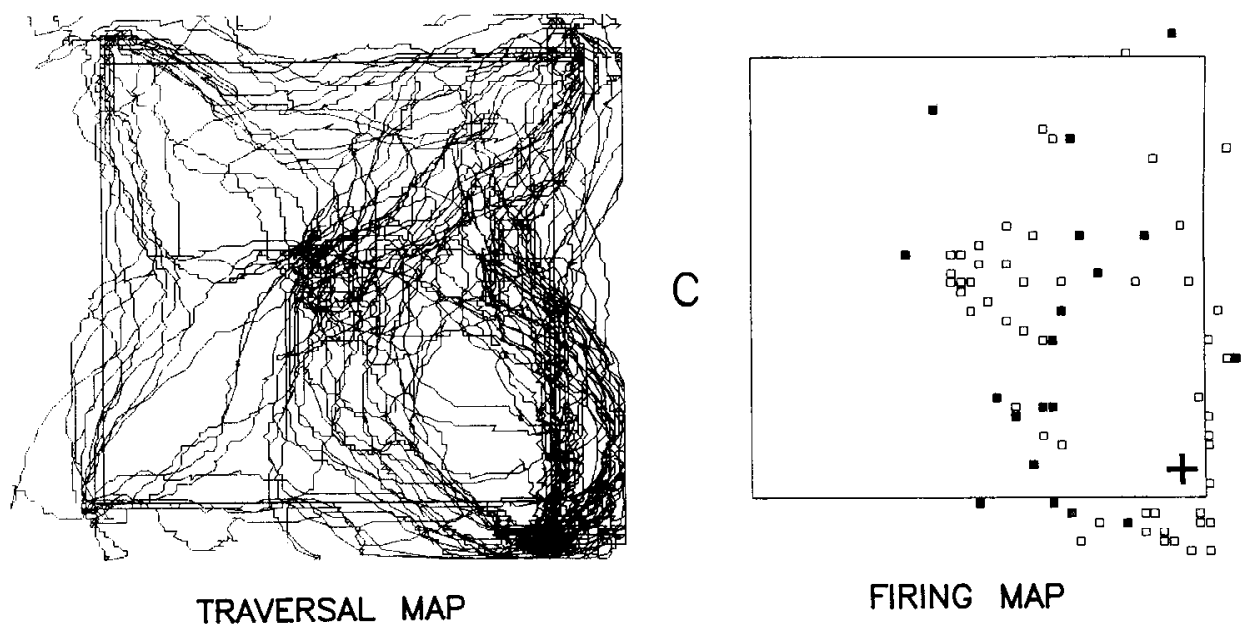

FIRING MAP

their time-shift calculations. We have examined both of these possibilities and accounted for each in our time-shift calculations. Under these conditions, field size was minimal and diverged maximally and symmetrically as the spike array was shifted forward and backward in time from the instant of spike occurrence. Hence, our results failed to support the supposition presented by Muller and Kubie (1986) that place cells fire in anticipation of arrival at a spatial location different from that at the time of spike occurrence.
The disruptive effect of barriers on place cell discharge was similar to that reported by Muller and Kubie (1987) and supports their conclusions regarding "kinematic" factors controlling firing within the place field. Barriers strategically placed to block traversal patterns within a given place field were effective in attenuating firing (Fig. 6), even though the animal might traverse the field using a different route (e.g., circling behind the barrier). Barriers that did not bisect or block an established traversal pattern did not significantly affect location-specific fir- 

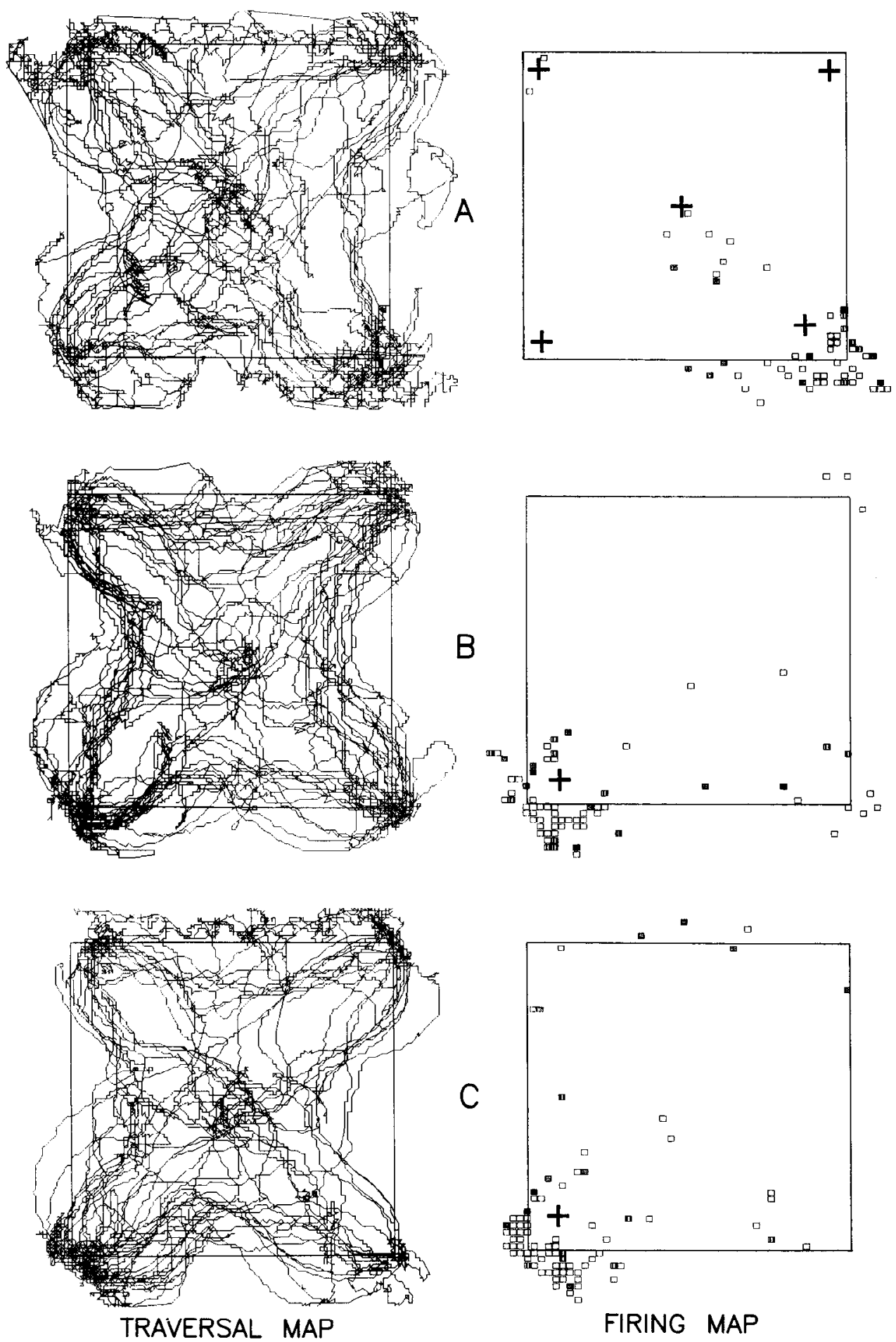

Figure 12. Time course of change in place field firing following selective baiting procedure. $A$, Random baiting condition revealed a place field in the back right corner of the platform. $B$, Following selective baiting of the back left water cup, the place field shifted to that location with residual firing in the previous place field location. Total elapsed time from initiation of selective baiting condition to end of recording session in $B$ was $15 \mathrm{~min}$. Time of recording session in $B$ was $7 \mathrm{~min}$. $C$, Results following an additional $7 \mathrm{~min}$ of selective baiting of the same location. Recording was continuous from $B$. Note animal still traversed the original place field, but very little firing occurred by the end of the session shown in $C$. The animal was on the platform continuously without interruption for sessions $A-C$.

ing (see Muller and Kubie, 1987). However, because the introduction of barriers interfered with relative and absolute directional sensitivity, both of which were shown to be critical correlates of within-field firing, it is difficult to ascertain the contribution of any single factor to the "barrier effect." In addition, the path required to circumvent the barrier might place the animal outside the field boundary, thereby producing a reduction in firing because of the animal's inability to physically cross the border on established trajectories. The increased bias of firing on inward versus outward trajectories further suggests the barrier effect would be most influential on reducing cell firing associated with entry into the field (see Table 1).

\section{Plasticity of place fields}

Place cell firing in these studies demonstrated the capacity to change from one location on the platform to another. That such shifts were produced by relatively simple changes in baiting procedures and occurred in a comparatively short time period 
(8-30 min) suggests that contextual factors determining the spatial location of place cell firing may be different from those operating to maintain firing within the field. To our knowlcdgc, this is the first time that this type of plasticity has been demonstrated for spatial correlates of complex spike cells.

The ability to alter place field expression has been suggested in demonstrations where place field firing was changed by rearranging or removing spatial cues (Muller and Kubie, 1987) or by disorienting the animal (Hill and Best, 1981). Preliminary reports from other investigators have demonstrated phenomena that appear to be somewhat similar to these findings (Bostock et al., 1986; Quirk et al., 1987). Since such field shifts could be explained either by disruption or rearrangement of spatial cues, it cannot be concluded that the shifts reported by these investigators and the shifts that occurred in the present study through selective baiting resulted from similar processes. The fact that firing characteristics (interspike distance, time, and velocity) within the shifted place fields in the current study were similar to thosc before the shift indicates the same cell was being sampled under both conditions. However, the shifted fields provoked more rigid traversal patterns (i.e., fewer turns) than the original place fields, resulting in a tendency for the cell to discharge along a narrower trajectory leading to the center of the field.

The locations in which place cells fired on the platform appeared to depend on their "significance" with respect to water delivery. There was no attempt to specifically "condition" visits to the baited cup during the selective baiting procedure since intervals between water delivery to the baited cup could be as long as 2-3 $\mathrm{min}$. Nevertheless, in several cases, a difference in traversal pattern was detected after less than 10 min of exposure to these conditions (Fig. 12), and it was therefore possible that some type of conditioning occurred. However, neither an increase in traversal of the new field nor a decrease in occupancy of the original field location appeared to be critical for shifting the place field (Figs. 9, 11). On the other hand, maintained baiting of the original field location (at the same time as baiting a new location) resulted in preservation of the original place field. A partial shift back to the original firing location and "dissolving" of the shifted place field was produced by reinstating the random baiting procedure (Fig. 10). This confirmed the plastic nature of the shift and indicated that specificity and contextual control over place cell firing tendencies could be readily demonstrated in the same cell.

The capacity to shift place fields from one location to another by this procedure indicates place cell responsiveness to factors that change the relevance of spatial locations. Studies by Eichenbaum and coworkers (Eichenbaum et al., 1987; Wiener et al., 1987) showed that complex spike cells with place correlates fired in 2 distinct locations of the apparatus during performance of an odor-discrimination task: (1) the area where the odor cue was sampled and (2) along a pathway leading to the reward location. Under these conditions, a large number of cells sampled in different animals exhibited similar discharge patterns to odor presentation and reward delivery. Given the current findings, it is interesting to speculate whether the cells recorded by Eichenbaum et al. (1987) were place cells that originally fired in different locations but were altered by training. Since distinct locations in the apparatus were consistently and exclusively associated with reward delivery, the execution of the instrumental response within these areas would be expected to acquire considerable significance. In a recent report, Paul et al. (1987) showed place field firing could be changed by shifting the location of reward in much the same manner as described here for the platform. There appears to be emerging evidence that place fields can be altered by manipulation of the location of biologically relevant or associatively conditioned stimuli. Therefore, it is important to determine (1) if these cells are responding within the spatial domain only and simply adjust by changing the "coordinates" of the place where the reward is located, or (2) if a reward contingency (no matter how trivial) has a predisposed controlling influence over the spatial firing attributes of these cells, thereby providing the capacity to code the significance of location in terms of reward availability.

In the current study, place cells were not selected for their propensity to shift location, yet 40 of 47 place cells demonstrated shifts. It may therefore be assumed that a significant proportion of place cells retain this ability. This suggests representation of spatial location by hippocampal cells may not occur unless that location has acquired significance for the animal. This would relegate hippocampal place cell firing to the same status as other correlates of hippocampal cell activity (see Segal, 1973; Berger et al., 1980; Moore and Solomon, 1980; Gabriel et al., 1986; Berger and Sclabassi, 1988). Best and Thompson (1984) reported that place cells showed conditioning-related changes in discharge to a tone stimulus after rats were subjected to conditioned emotional response training. However, Christian and Deadwyler (1986) were unable to demonstrate a statistically significant change in firing of place (complex spike) cells during a 2-tone appetitive discrimination task. The lack of place cell conditioning in the Christian and Deadwyler (1986) study may reflect that animals were well conditioned in the discrimination task prior to testing for place field correlates, whereas in the Best and Thompson (1984) report, animals were not conditioned until after place field firing was assessed. The marked propensity for place fields to shift location following selective baiting in this study may indicate that place cells are more readily conditioned under circumstances in which spatial attributes of the environment are relatively sterile (i.e., only a single cue card was used to provide a spatial reference within the apparatus).

\section{Significance versus place}

Recently it has been reported that hippocampal place cells are capable of retaining specific configurations of spatial cues when those cues are no longer present (O'Keefe and Speakman, 1987). These reports provide compelling evidence for the notion that hippocampal cells have the ability to maintain firing characteristics under circumstances in which the environmental cues are altered. In that study, place cells did not fire at any time in relation to the location of reward (goal box). However, all animals tested were previously conditioned to make a particular response (i.e., turn right or left) to obtain reward in the goal box. Hence, the goal box per se was no longer significant, but the route to the goal box was. Therefore, cell firing could have been related to the significance of the appropriate turn in the maze, not the location of the reward since that was predetermined given the appropriate turn. The significance of firing may not always be related to coding the reward location but, perhaps more important, to coding key aspects of a route to that location.

In a number of circumstances reported in the literature there have been convincing demonstrations of increases in hippocampal complex spike cell discharge related to the acquired signif- 
icance of a prominent cue within an experimental context. This tendency for hippocampal complex spike cells to exhibit multiple firing correlates has led to confusion among investigators as to precisely which behavioral correlates reflect unique information encoded by hippocampal neurons (see Moore and Solomon, 1980; Wible et al., 1986). The demonstrated capacity for hippocampal cells to change place field firing has not been explicitly demonstrated before this paper was submitted for publication; however, many recent investigations have provided examples of changes in hippocampal place cell firing patterns that are indicative of such plasticity (see above). Most notable among these are the dilation of the place field resulting from upward scaling of the dimensions of the cue controlled enclosure reported by Muller and Kubie (1987). In addition, the propensity for large numbers of place cells to fire in areas of the apparatus associated with reward or response execution in the conditioning studies of Eichenbaum et al. (1987) are quite supportive of the plastic nature of the complex spike cells. Given the findings in this study, it is now possible to extend hippocampal complex spike cell plasticity to include spatial firing, which was previously thought to be a relatively inflexible behavioral correlate. The rigidity of spatial relations between elements in the environment may predispose hippocampal complex spike cells to code for spatial features in the absence of other contextually relevant stimuli. Complex spike cells, however, appear to retain the flexibility to alter even spatial-encoding properties when other spatial locations within the environment acquire bchavioral or cognitive significancc.

\section{References}

Berger, T. W., and R. J. Sclabassi (1988) Long-term potentiation and its relation to hippocampal pyramidal cell activity and behavioral learning during classical conditioning. In Long-Term Potentiation: From Biophysics to Behavior, P. W. Landfield and S. A. Deadwyler, eds., pp. 467-497, Liss, New York.

Berger, T. W., R. I. Laham, and R. F. Thompson (1980) Hippocampal unit-behavior correlations during classical conditioning. Brain Res. 193: 229-248

Best, P. J., and J. B. Ranck, Jr. (1982) The reliability of the relationship between hippocampal unit activity and sensory-behavioral events in the rat. Exp. Neurol. 75: 652-664.

Best, P. J., and L. T. Thompson (1984) Hippocampal cells which have place field activity also show changes in activity during classical conditioning. Soc. Neurosci. Abstr. 10: 125.

Bostock, E., R. U. Muller, and J. L. Kubie (1986) Firing fields of hippocampal neurons: A stimulus manipulation that alters place cell mapping of the environment. Soc. Neurosci. Abstr. 12: 522 .

Breese, C. R., R. E. Hampson, and S. A. Deadwyler (1987) Direction contingent firing of hippocampal place cells. Soc. Neurosci. Abstr. 13: 608.

Christian, E. P., and S. A. Deadwyler (1986) Behavioral functions and hippocampal cell types: Evidence for two nonoverlapping populations in the rat. J. Neurophysiol. 55: 331-348.

Deadwyler, S. A., J. Biela, G. Rose, M. West, and G. Lynch (1979a) A microdrive for use with glass or metal microelectrodes in recording from freely-moving rats. Electroencephalogr. Clin. Neurophysiol. 47: $752-754$.

Deadwyler, S. A., M. O. West, and G. S. Lynch (1979b) Activity of dentate granule cells during learning: Differentiation of perforant path input. Brain Res. 169: 29-43.

Eichenbaum, H., M. Kuperstein, A. Fagan, and J. Nagode (1987) Cuesampling and goal-approach correlates of hippocampal unit activity in rats performing an odor discrimination task. J. Neurosci. 7: 716732.
Foster, T. C., E. P. Christian, R. E. Hampson, K. A. Campbell, and S. A. Deadwyler (1987) Sequential dependencies regulate sensory evoked responses of single units in the rat hippocampus. Brain Res. 408: 86-96.

Fox, S. E., and J. B. Ranck, Jr. (1981) Electrophysiological characteristics of hippocampal complex-spike and theta cells. Exp. Brain Res. 41: 399-410.

Gabriel, M., S. P. Sparenborg, and N. Stolar (1986) An executive function of the hippocampus. Pathway selection for thalamic neuronal significance code. In The Hippocampus, R. L. Isaacson and K. H. Pribram, eds., pp. 1-40, Plenum, New York.

Hill, A. J., and P. J. Best (1981) Effects of deafness and blindness on the spatial correlates of hippocampal unit activity in the rat. Exp. Neurol. 74: 204-217.

Kubie, J. L., and J. B. Ranck, Jr. (1983) Sensory-behavioral correlates of individual hippocampal neurons in thrèe situations: Space and context. In Neurobiology of the Hippocampus, W. Siefert, ed., pp. 433-447, Academic, New York.

McNaughton, B. L., C. A. Barnes, and J. O'Keefe (1983) The contributions of position, direction and velocity to single unit activity in the hippocampus of freely moving rats. Exp. Brain Res. 52: 41-49.

Moore, J. W., and P. R. Solomon, eds. (1980) The Role of the Hippocampus in Learning and Memory. A Memorial Workshop to A. H. Black, Vol. 8, Physiological Psychology, Psychonomic Society, Austin, TX.

Muller, R. U., and J. L. Kubie (1986) Introduction of time into the study of place cells. Soc. Neurosci. Abstr. 12: 521 .

Muller, R. U., and J. L. Kubie (1987) The effects of changes in the environment of the spatial firing of hippocampal complex-spike cells. J. Neurosci. 7: 1951-1968.

Muller, R. U., J. L. Kubie, and J. B. Ranck, Jr. (1987) Spatial firing patterns of hippocampal complex-spike cells in a fixed environment. J. Neurosci. 7: 1935-1950.

O'Keefe, J. (1979) A review of the hippocampal place cells. Prog. Neurobiol. 13: 419-439.

O'Keefe, J., and D. H. Conway (1978) Hippocampal place units in the freely moving rat: Why they fire where they fire. Exp. Brain Res. 31: 573-590.

O'Keefe, J., and J. Dostrovsky (1971) The hippocampus as a spatial map. Preliminary evidence from unit activity in the freely-moving rat. Brain Res. 34: 171-175.

O'Keefe, J., and L. Nadel (1978) The Hippocampus as a Cognitive Map, Oxford U. P., Oxford, UK.

O'Keefe, J., and A. Speakman (1987) Single unit activity in the rat hippocampus during a spatial memory task. Exp. Brain Res. 68: 127.

Olton, D., M. Branch, and P. Best (1978) Spatial correlates of hippocampal unit activity. Exp. Neurol. 58: 387-409.

Paul, C. A., S. I. Wiener, and H. Eichenbaum (1987) Behavioral correlates of hippocampal place cells. Soc. Neurosci. Abstr. 13: 1318.

Quirk, G. O., R. U. Muller, J. L. Kubie, and J. B. Ranck, Jr. (1987) Hippocampal and entorhinal place cells: What happened when the lights went out? Soc. Neurosci. Abstr. 14: 1331.

Segal, M. (1973) Flow of conditioned responses in limbic telencephalic system of the rat. J. Neurophysiol. 36: 840-854.

Wible, C. G., R. L. Findling, M. Shapiro, E. J. Lang, S. Crane, and D. S. Olton (1986) Mnemonic correlates of unit activity in the hippocampus. Brain Res. 339: 97-110.

Wiener, S. I., H. Eichenbaum, C. A. Paul, and M. Kuperstein (1987) Hippocampal "decision" cells in rats in a simultaneous-cue odor discrimination task. Soc. Neurosci. Abstr. 13: 1319.

Zipser, D. (1985) A computational model of hippocampal place fields. Behav. Neurosci. 99: 1006-1017.

Zipser, D. (1987) Biologically plausible models of place recognition and goal location. In Parallel Distributed Processing. Explorations in the Microstructure of Cognition. Vol. 2: Psychological and Biological Models, J. L. McClelland, D. E. Rumelhart, eds., pp. 432-470, MIT Press, Cambridge, MA. 